\title{
EL DIÁLOGO ENTRE AUTÓCTONOS E INMIGRAN- TES A PRUEBA EN TIEMPO DE CRISIS: EL CASO DE LOS SENEGALESES EN COSTA DE MARFIL
}

\author{
Kouadio ALEXIS LALLY \\ Universidad Péléforo Gon Coulibaly de Korhogo
}

Recibido: 04/03/2012

Aceptado: 04/11/2013

RESUMEN: El mundo se aferra a solucionar la crisis que le aqueja desde hace unos años pero Costa de Marfil tiene que solucionar la suya propia, a consecuencia del conflicto político-social y militar que empezó en 2002 y que todavía tiene cierta repercusión a pesar de haber finalizado en 2011. En este artículo se presenta un estudio descriptivo en torno a los inmigrantes senegaleses que viven en Costa de Marfil. Después de una breve introducción, se hace un esbozo epistemológico de la inmigración senegalesa en Costa de Marfil antes de abarcar el estudio propiamente dicho. La metodología aplicada en la investigación se basa en el acercamiento al punto de vista de la comunidad implicada, a través de la técnica de las historias de vida. Acabamos con los resultados que recogen los motivos que les llevaron Costa de Marfil- cuestiones de diálogo entre comunidades- la asociación y los problemas preliminares- el advenimiento de la crisis y sus problemas.

PALABRAS CLAVE: Migración, crisis, desarrollo, dialogo.

ABSTRACT: The world clings to solve the crisis that afflicts him since many years but Ivory Cost must solve hers own one, as a result of the political, social and military conflict that began in 2002 and which still having certain repercussion in spite of to have finalized in 2011. In this article we present a descriptive study about the Senegalese immigrants who live in Ivory Coast. After a brief introduction, we make an epistemological outline of the Senegalese immigration in Ivory Coast before including the proper study. The methodology applied in the investigation is based on approach to the point of view of the implied community, through the technique of the life stories. We end with the results that pick up the reasons for going to Ivory Coast-questions of dialogue between communities- the association and preliminary problems- the coming of the crisis and its problems.

KEYWORDS: migration, crisis, developpement, dialogue.

\section{INTRODUCCIÓN.}

En Europa, los flujos migratorios procedentes de África generan un tratamiento mediático, político y científico profundizado que busca entenderla para aportar soluciones duraderas para bien de la población receptora y también de los 
inmigrantes. Muy a menudo, los movimientos migratorios que se desarrollan en África pierden interés o se desconocen pero en realidad, la migración intracontinental en África es muy importante. Mucha gente de a pie tiende a creer que el migrante africano sólo tiene como objetivo llegar a Europa y no siempre es así. A veces, Europa es sólo el último tramo de un periplo que empieza en otros países de acogida como, Costa de Marfil, Gabón, Marruecos, Libia, etc. Estos movimientos, como casi siempre, están relacionados con las recomposiciones socioeconómicas, culturales y religiosas de nuestras sociedades africanas. Nuestro cometido en este trabajo es hacer conocer específicamente la inmigración senegalesa en Costa de Marfil bajo algunos de los aspectos de sus vivencias antes, durante y después de la crisis que vivió el país. Algunas preguntas nos sirven de marco para este quehacer, como por ejemplo: ¿La crisis que vivió Costa de Marfil cuestionó los valores morales marfileños basados en la acogida y en solidaridad con los extranjeros? ¿Cómo ha ido evolucionando el trato a los a los inmigrantes a los largo de las últimas décadas?

Estas preguntas sólo no sirven para aportar más material al debate empezado en otros trabajos acerca de las lacras en el proceso de desarrollo del continente africano.

\section{APROXIMACIÓN EPISTEMOLÓGICA A LA INMIGRACIÓN SENEGA- LESA EN COSTA DE MARFIL.}

Para entender las causas de la presencia senegalesa en Costa de Marfil hay que remontar a la política migratoria ideada por los diferentes gobiernos que se han sucedido en el poder. Como bien dicen Kouadio Brou y Yves Charbit ${ }^{1}$, se explica por la necesidad de mano de obra cualificada en el marco de la construcción de los territorios franceses de África, igual que ocurrió en el caso de Gabón y de Camerún.

Costa de Marfil defendió durante muchos años una posición pro-natalista en materia de inmigración fundamentada en la idea que la puesta en valor de las riquezas minerales, energéticas y agrícolas necesita mucha mano de obra. A partir de entonces, una población abundante es percibida como la condición esencial de desarrollo. Así pues, tan pronto como se independizó Costa de Marfil en 1960, el objetivo prioritario fue aumentar su población, entre otras medidas, como las ventajas que acompañan cada maternidad o la interdicción del aborto. Se invitó a los países limítrofes a venir en Costa de Marfil y a instalarse para trabajar. Los

${ }^{1}$ Brou, Kouadio y Charbit, Yves (1994). «La politique migratoire de la Côte d'Ivoire». En REMI, Vol 10, 3, pp.33-59. 
malíes, los burkinés, los ghaneses, los guineanos, los senegaleses, etc., se instalaron en Costa de Marfil con proyectos diferentes de realización socio-económica ${ }^{2}$. En vez de trabajar en los campos venían a ser profesores de los institutos o a ser comerciantes.

Hoy en día con más de $26 \%$ de población inmigrante, Costa de Marfil constituye el principal país de inmigración del oeste africano. El fuerte crecimiento económico del país en los años 70 constituyó un potente factor llamada. No obstante, esta presencia no es ni mucho menos reciente. Su visibilidad sólo se acentuó al pasar de los años. En 1965 había un $17 \%$ de extranjeros, un $22 \%$ en 1975 y un $28 \%$ en 1988.

La primera fase de la inmigración senegalesa empezó en $1893^{3}$. Eran esencialmente soldados desmovilizados y marabúes. Los soldados que cumplían su servicio militar con los franceses ayudaron a los franceses a luchar no sólo contra Samory Touré pero también a pacificar todo el territorio. Esta pacificación hacía posible la circulación de las personas y de los bienes por todo el territorio marfileño. A este respecto decía el Gobernador Clozel:

«...los senegaleses (Toucouleurs, Wolofs, etc.) vinieron a la colonia como soldados, guardias de policía, obreros de arte, comerciantes etc. Su número no excedía unos centenares» ${ }^{4}$ (traducido del francés)

Una vez desmovilizados, se quedaron cerca de sus guarniciones situados en el litoral de Gran-Bassam, primera capital del país entre 1893 y 1896. Llegaron a alcanzar 300 personas en 1913. Entre ellos, los wolof luego demostraron su pericia en la albañilería y panadería, un saber adquirido en su desempeño militar. Según, Triaud (1974), pocos trabajaron en la administración colonial. Algunos, particularmente los toucouleurs se quedaron como guías religiosos ${ }^{5}$ musulmanes.

${ }^{2}$ A los burkineses, a los malíes, se les encontraba mucho en el sector de la agricultura, los senegaleses en el comercio. Entre los ghaneses había albañiles, electricistas. Los benineses eran profesores en su gran mayoría.

${ }^{3}$ DAOUdA, Gary (2003). «Les mutations de la dynamique migratoire des Soudanais-Maliens en Côte d'Ivoire, 1908-1980».En Coquery-Vidrovitch, C., Goerg, O., Mandé, I., Rajaonah, F., (eds). Etre étranger et migrant en Afrique de l'ouest au XX ème siècle. Enjeux identitaires et modes d'insertion. Volume II. Paris: l'Harmattan, pp. 239-261.

${ }^{4}$ Clozel (1902). Le recensement de 1901 à la Côte d'Ivoire. Bulletin du comité de l'Afrique française, 4 avril 1902, pp. 141-142.

${ }^{5}$ Enseña el Corán antes de instalarse como negociantes o explotadores agrícolas. Hoy vemos en a muchas comunidades musulmanes cortar la carretera para rezar. Sin embargo, los primeros en 
La segunda fase de la inmigración senegalesa se sitúa entre 1889 y 1945. La colonización francesa, contribuyó fuertemente en ello. Los senegaleses eran gerentes de almacenes o jefes de sucursales en Saint-Louis, Gorée y Dakar. Desde 1920 hacían negocios con los franceses pero poco a poco los grandes comercios franceses empezaron a echar abajo a esta burguesía comerciante. Para evitar la quiebra total, según Zie \& Vrih, (1992), se fueron en exilio en Costa de Marfil. Sus empresas se desarrollan entorno a redes familiares cuando no se asociaban con europeos o no se ponían a su servicio.

La última fase empezó con la bonanza económica, en los años posteriores a la independencia y se incrementó en los años 80. En 1988 después del censo general de la población, con 40.000 senegaleses (RGPH, 1988), constituían la segunda comunidad más importante de su país de origen en el extranjero. Hoy en día (en 2013), según el primer consejero del Consulado de Senegal en Costa de Marfil, se estima en 50.000 personas el número de senegaleses en Costa de Marfil, aunque durante los últimos comicios presidenciales en Senegal, el número de los inscritos ascendían a 15.700. La diferencia se explica por el número de los no apuntados y de los niños. La mayoría se encuentra en Abidjan, pues según los informes, sobre los 15.700 registrados en la lista electoral, 11.000 viven en Abidjan.

Muy dependientes del comercio colonial, no pudieron consolidar su posición en la economía marfileña, pero muchos se reconvirtieron en pequeños comerciantes.

Hoy en día, la inmigración senegalesa se reparte por toda la geografía del país, con especial mención a Abidjan, la capital económica, por la importante actividad económica de esta urbe ${ }^{6}$. Treichville ${ }^{7}$ es su barrio emblemático. Es una migración de hombres solos que llegan a Abidjan donde ya viven miembros de la comunidad o de la familia.

\section{METODOLOGÍA}

Esta contribución es un estudio cualitativo descriptivo desarrollado desde un enfoque biográfico-narrativo; esta perspectiva nos resultó bastante interesante para comprender el punto de vista de las personas implicadas en la investigación con el

instituir la oración pública y construir mezquitas en el suroeste del país fueron ellos. A tal punto que su influencia espiritual iba más allá de la comunidad senegalesa.

${ }^{6}$ Esta tendencia a vivir en las ciudades grandes se nota tanto en España como en Francia donde se les encuentran en mayoría en las ciudades grandes como Madrid, Barcelona o Paris.

${ }^{7}$ En los años sesenta, era el barrio de los negocios y como la estrategia de alojamiento sigue la pauta habitual de los migrantes (tendencia a la reagrupación) muchos han seguido la estela de los primeros. 
fin de que puedan dar a conocer su día a día desde una perspectiva subjetiva. Los relatos de vida, como ya sabemos, son de un interés para la antropología ya que permiten conocer, mediante narraciones autobiográficas, las experiencias de los narradores. J. Pujadas ${ }^{8}$ (1992) señala que la historia de vida aporta una evidencia fundamentalmente cualitativa sobre la percepción del informante acerca de cierto evento o problema. J.I. Ruiz Olabuénaga (1999) asegura que la historia de vida permite captar la totalidad de una experiencia biográfica...en el tiempo y en el espacio (...) captar la visión subjetiva con la que uno se ve a sí mismo y al mundo (...) descubrir las claves de interpretación (...) de fenómenos sociales de ámbito general que sólo encuentran explicación a través de la experiencia personal de los individuos concretos. La muestra de nuestro estudio se basó en personas que por razón de edad u ocupación disponen de mayor información. En nuestro muestreo, hubo 10 relatos de vida de informantes senegaleses que viven en Costa de Marfil (4), Francia (3) y España (3). Una vez obtenidos los relatos, se realizó una lectura detenida para luego hacer el análisis. No se ha cuidado especialmente el anonimato de los sujetos que aparecen a lo largo del estudio porque no vieron ningún inconveniente en que pongamos su nombre. Estas historias de vidas se desarrollaron de manera distendida y el contenido quedó grabado en audio previa autorización de los informantes. Además de las historias de vida, se realizaron algunas entrevistas asimétricas ${ }^{9}$ en Costa de Marfil para completar la información y extender la investigación a una buena parte del colectivo. Esta forma de entrevistas confiadas a miembros del grupo estudiado por el propio investigador tiene como objetivo «romper el hielo» que suele haber cuando se trata de investigar un colectivo del que uno no es parte.

Por último, la observación participante en Costa de Marfil, nos permitió llegar a un conocimiento del colectivo tanto en su territorio de origen como en algunos países tradicionales de emigración. 20 senegaleses constituyeron la muestra de nuestra observación participante en Costa de Marfil. En España y en Francia, pudimos investigar de forma preliminar al colectivo senegalés y eso nos permitió llegar a comparativas sobre las vivencias culturales de este colectivo. Las entrevistas en profundidad nos sirvieron para recuperar aquellos datos que la observación por sí sola no nos permitía obtener.

${ }^{8}$ Pujadas Muñoz, J.J (1992) El método biográfico: el uso de las historias de vida en ciencias sociales. Madrid, CIS, Centro de Investigaciones Sociológicas.

${ }^{9}$ Fernández Álvarez, Ó. y GonzÁlez Arpide, J.L (2002). «Inmigrantes en León. Elementos teóricos y prácticos». Estudios humanísticos. Historia, 1, pp. 333-353. 


\section{RESULTADOS}

\subsection{Los motivos para venir en Costa de Marfil}

Los modelos clásicos en torno a qué motiva la emigración propician un debate sobre el proceso migratorio en términos de atracción-expulsión y lo explican como una válvula de escape de la población activa en un momento determinado. En el caso de senegaleses en Costa de Marfil empezó como una ayuda a la colonización pero acabo siguiendo las pautas normales de la emigración en los términos arriba mencionados. Por lo que hemos enfocado nuestra investigación sobre razones actuales de la emigración.

Ya hemos anticipado razones históricas a la inmigración senegalesa en Costa de Marfil ya que participaron a la pacificación del país durante la fase de colonización del país por los franceses. No obstante, para nuestros informantes la nueva inmigración viene motivada por razones como la escasez de oportunidad económica que existe en su país. Esta intervención es de Mbaye:

«...me llamo Mbaye. Soy senegalés de la ethnia wolof. Vivo en Costa de Marfil desde1991...como los wolof somos un pueblo de comerciantes, queremos tener éxito en el comercio. En Senegal, hay cada vez menos sitio para tener un buen negocio. Hay que salir e ir a otro país si quieres prosperar. Y yo, en su tiempo, elegí a Costa de Marfil porque la situación económica era mejor. Bueno, hace 22 años ahora...Además Costa de Marfil es un país hermano...» (Traducido del francés)

La falta de trabajo matiza un poco más esa escasez de oportunidades en la tierra de origen, de forma que hacían que la calidad de vida fuese nula. Dadas las dificultades económicas, la finalidad del viaje era la búsqueda del ahorro para poder realizarse en origen. Los predecesores son un ejemplo que quieren copiar, dixit Mbaye:

«...los senegaleses vinieron en Costa de Marfil hace mucho tiempo, incluso antes de la independencia. Tenía un tío que vivió y murió en Costa de Marfil. Llegó en los años 60 ...la gente como él ganó mucho dinero porque el país estaba en pleno desarrollo. Mi tío tenía casas en Senegal, en el pueblo y en la capital. Gracias a él nuestra familia es muy respetada. Al principio, compraba productos agrícolas y los volvía a vender. Luego transformó su almacén en tienda de alimentos en Treichville... Yo era joven en Senegal y como no tengo estudios, quería hacer el comercio pero no tenía dinero... él me ayudó a venir...» (traducido del francés) 
Como vemos, el push and pull factors fue esgrimido en su tiempo por la perspectiva neoclásica ${ }^{10}$, defendida por Todaro $^{11}(1969,1976,1989)$ y Borjas ${ }^{12}$ (1989) en su enfoque microestructural. Para ellos, son los determinantes de la emigración y eso sigue siendo muy actual y se aplica a cualquier tipo de investigación sobre inmigración. La inmigración senegalesa no deroga a la regla. ¿Si las fronteras de los dos países no parecían existir por la facilidad que se otorgaba al colectivo para llegar a Costa de Marfil, se puede decir que el diálogo entre comunidades era una realidad o una vista del espíritu? Una de las formas de saberlo, es interesarnos a su forma de integración intra y extracomunitaria.

\subsection{Cuestiones de diálogo entre comunidades}

Este diálogo, lo vemos como el proceso de integración de la comunidad senegalesa en Costa de Marfil. Abarca muchos aspectos como, la vida social, el trabajo, o la vida asociativa a los que nos vamos a interesar de modo peculiar.

Estas dos intervenciones nos permiten dar algunos indicios de como muchos senegaleses vivían su integración social en el país. El consejero de la Embajada nos libra su punto de vista al respecto:

«...vivimos en un país que ahora tiene problemas y todos le tiran la piedra...es fácil pero hay que decir que los marfileños son muy buena gente. Siempre han respectado a los senegaleses... vivimos aqui desde hace muchas décadas. Como existe una buena relación entre los dos países, no tenemos problemas de aceptación. No somos conflictivos y eso cuenta mucho cuando vives en un pais...» (traducido del francés)

Mbaye, también comparte su punto de vista:

«...algunos, vivimos bien y no nos quejamos...si después de todo seguimos viviendo aqui es porque no sentimos bien aqui. No tengo reproches en contra de los marfileños porque si una persona me ofende no puedo decir que todos me han ofendido. No puede decir que los marfileños son malos...trabajo sin problema, me llevo bien con la gente. Es verdad que cada

${ }^{10} \mathrm{El}$ enfoque microestructural de la teoría neoclásica se plasma en la explicación de las razones por las cuales los individuos responden a las diferencias estructurales entre países o regiones para emprender la migración.

11 TodARO, M.P. (1969) «A model of labour migration and urban unemployment in less developed countries». En American Economic Review, no 59, pp. 138-148; TODARO, M.P. (1976) Internal Migration in Developing Countries. Geneva International Labor Office; TODARO, M.P. (1989) Economic Development in the Third World. New York, Longman.

12 BorJAS, G.J. (1989) «Economic theory and international migration». En International Migration Review, 23, pp. 457-485. 
uno tiene su carácter, asi hay gente con los que es fácil vivir y otros no, y eso se ve en todas partes en el mundo...» (traducido del francés)

Ahora bien, la buena convivencia social entre marfileños y senegaleses no significa ausencia de problemas. La mayoría de estos problemas vienen del propio colectivo. La mayoría de las dificultades al llegar a Costa de Marfil se centraban en el idioma. Senegal y Costa de Marfil tienen en común, el ser colonias francesas con el francés como lengua. Sin embargo, mientras Costa de Marfil ce centró en el francés como lengua para federar la muchedumbre de lenguas nativas (61), Senegal, promovía el Wolof como lengua nacional. Muchos de le senegaleses que vienen no saben hablar el francés por lo que el enclave étnico era el lugar de expresión durante los primeros momentos de llegada. La historia de vida de Mouss es nos da una idea de esta contingencia de su presencia en Costa de Marfil. Llegó en 1998 a mano del amigo de su padre, ahora de vuelta a Senegal.

«tuve algunos problemas cuando llegué. No podía hacer cosas sólo porque no hablaba francés. Siempre estaba con compatriotas... fue también dificil a causa de algunos problemas porque las costumbres son diferentes. Yo que llegué desde el pueblo sin haber en una ciudad grande, veía Abidjan muy grande. La gente tenía otra manera de vivir. Son modernos...bueno no sé cómo explicártelo pero era diferente...» (Traducido del francés)

En muchas migraciones, las asperezas culturales son notables y los senegaleses no escapan de esta característica. Incluso en Costa de Marfil, donde parece fácil la adaptación del extranjero considerado el «hermano» por el padre de la nación, se producían situaciones que dificultaba la socialización:

la gente aqui tiene una forma de ser...si algunos son muy educados y cariñosos conmigo, otros te hacen recordar que eres un extranjero...

Como ya se ha indicado, la mayoría de los motivos de la emigración era encontrar trabajo por lo que las actividades laborales realizadas en el lugar de destino ocupan su tiempo y su sentir. Los trabajos que ejercen son muy variados y dependen fundamentalmente de la formación y de las necesidades del país de destino. Algunos vienen con una buena formación académica. Es el caso del señor $\mathrm{Ba}$ Mamadou, es un profesor jubilado y daba clase de francés en un instituto de la capital económica marfileña:

«...yo llegué con dos colegas senegaleses desde Dakar para la docencia. En aquel entonces, es decir a finales de los 70...se necesitaba muchos profesores en los institutos y por eso hemos venido. ...yo era profesor de francés, otro compañero llamado N'diaye era profesor de Matemáticas y Cheikh era docente de Ciencias naturales. Con los benineses, los que venimos a aportar nuestra contribución a la educación de la élite de este 
país...no hay quién diga que no ha tenido a un profesor senegalés o beninés...es la ivoirisation ${ }^{13}$ de los cuadros que hizo que muchos volvieron a su país. Y con ellos muchos senegaleses... yo segui dando clases en un Instituto hasta jubilarme...» (Traducido del francés)

En efecto, en 1975, los extranjeros oeste-africanos que representaban la quinta parte de la población marfileña fueron sometidos a un nuevo cuadro jurídico: la «ivoirisation» de los cuadros. Empezado en la esfera administrativa (creación de un ministerio de trabajo y de la ivoirisation de los cuadros». Esta política se extendió a muchos sectores de la actividad económica, incluso la enseñanza.

A la diferencia de los malíes y de los burkineses, nunca se verá a un senegalés trabajar en el campo en Costa de Marfil. Durante nuestra observación del colectivo, los $75 \%$ de los senegaleses son comerciantes, una actividad heredada de sus primeros momentos de presencia en el país. Sobre los 20 senegaleses que participaron en la investigación en Abidjan, 15 son wolof y se dedican a actividades comerciales como la venta de relojes, cinturones, gafas, camisas, joyas etc. Se encuentran en los mercados de Treichville, Cocody, Adjamé o de Koumassi. Mbaye es uno de ellos.

«...como decía, el comercio ${ }^{14}$ es nuestra actividad favorita en Senegal. Vendemos de todo, relojes, joyas, pequeñas cosas, cinturones, ropa, gafas...yo hoy vendo pañuelos de vestir. Es una actividad que muy pocos podemos hacer porque cuesta abrir una tienda de este tipo. Al principio sin embargo vendía lo mismo...» (traducido del francés).

La propensión de los senegaleses a ejercer en el sector del comercio hace que si bien, la «ivoirisation» afectó a unos senegaleses, muchos no han tenido que sufrir los efectos.

La integración laboral senegalesa no sólo abarca a los hombres sino también las mujeres. No se puede definir exactamente el número de senegalesas en Costa de Marfil pero hay un número importante según dicen los informantes. Más del $90 \%$ de las mujeres se integran en el comercio, en la costura, la venta de mercancías diversas ${ }^{15}$, o son sencillamente mujeres de hogar, estudiantes e incluso trabajan en

${ }^{13}$ Este neologismo viene del propio nombre del país y se puede comparar a españolización.

${ }^{14}$ Nuestras observaciones en Europa nos permitieron confirmar estas afirmaciones. En Madrid, en Barcelona, en París, es el mismo espectáculo con la salvedad de que en Costa de Marfil, esta actividad no se hace de forma ambulante.

${ }^{15}$ El comercio internacional es algo practicado por algunas. Algunas hacen cada poco, el viaje a Senegal para traer mercancías para venderla en Costa de Marfil. Sin embargo, al marchar cargan 
empresas. Las mujeres vienen por reagrupación, pero la segunda o tercera generación es mucho más importante en proporción.

Es este apartado, nos interesamos exclusivamente a la mujer senegalesa, en su entorno comercial más reconocido: la restauración, su verdadero marcador identitario en la sociedad marfileña y como fuente de reconocimiento laboral

Son las especialistas del apreciado plato llamado ceb bujën o ceb buwessen, la primera especialidad. La segunda se compone del arroz cocido a vapor aparte, el ñankatang. Se sirve con varios tipos de salsa: salsa de carne y manteca de cacahuete (mafe); salsa con pollo y cebolla (yasa); salsa de pescado, de carne con aceite de palma (supu kandia).

Amy es uno de ellas. Ella también nos libró su historia de vida.

«Vine aquí para vivir con mi marido en los años 2000. Soy la más joven de sus tres mujeres. Dos vivimos con él aqui y la tercera está en Senegal. Para criar a mis 4 hijos, me ayudó a abrir un restaurante. Sabes que en las familias donde existe la poligamia, el hombre tiene que proveer la comida pero en la práctica, es difícil, y las mujeres debemos luchar. La otra mujer hace comercio entre Senegal y Costa y yo debo apañármelas para criar a mis hijos. Tengo un restaurante y vendo el ceb que los marfileños aprecian...» (traducido del francés)

Este extracto nos permite sacar muchas conclusiones pero nos interesa aquí destacar que la comida senegalesa tiene mucha receptividad entre los marfileños, rasgo de una aceptación del colectivo.

«...como mi restaurante no está lejos del puerto, vendo la comida a los trabajadores del...les encanta el ceb. En todas partes en Abidjan, encontrarás esta comida ...incluso las marfileñas intentan copiarnos pero nunca lo harán tan bien como nosotras, las senegalesas ... y eso que no encontramos muchos ingredientes aquí...la solución a eso es tomar cosas de aquí para reemplazar lo que falta...además, doy un toque marfileño a mi ceb ...es decir que me adapto a algunos ingredientes de aquí...donc je sais des choses deahora soy una especialista del ceb e incluso cuando vuelvo a Senegal, se nota en el ceb que hago una mejora...la gente quiere lo que hago...» (traducido del francés)

Hay en estas palabras de Amy, una manifestación de lo que Jean-Pierre

cartones llenos de Attiéké, una comida muy apreciada por los senegaleses, en origen y por la comunidad marfileña que vive en este país. 
POULAIN ${ }^{16}$ llama la relocalización de la alimentación. Conlleva muchas veces una micro-adaptación al gusto del mercado local. Para este autor, Mac Donald también hizo lo propio en Francia añadiendo a sus recetas cosas apreciadas por los franceses.

Los senegaleses de León, cuando cocinan usan elementos culinarios locales para adaptarlos a falta de algo típico del país ${ }^{17}$. El no encontrar un paliativo hace que la reproducción exacta del plato es imposible. Se producen, a veces innovaciones.

La homogeneización de las prácticas es de descartar ya que los senegaleses guardan sus costumbres alimenticias, signos de su identidad, intentando sin embargo sacando algunos complementos para mejorar sus comidas. Como dice Bouly de Lesdain ${ }^{18}$ hay una resistencia al cambio de la alimentación. Instalándose en Costa de Marfil, eligieron adaptar durablemente sus artes culinarias. Como apunta Stefannia CAPONE ${ }^{19}(2004,2011)$ «el proceso de 'desterritorialización', en el sentido de desubicación, rara vez se hace sin una 'reterritorialización', asentarse en otro lugar. El desplazamiento exige una producción que permite anclar de nuevo lo que fue 'desterritorializado' en nuevos espacios, reales o simbólicos».

Es de preguntarnos si el diálogo cultural entablado a través de la vía de la comida, tiene reconocimiento, tanto entre los senegaleses como entre los marfileños. Esta intervención de Mbaye nos sitúa al respecto:

"...hay cosas que no me gustan. El foutou por ejemplo no es algo que no me gusta particularmente. Pero eso no quiere decir que a todos los senegaleses no les gusta la comida marfileña. De hecho, conozco a muchos

16 Poulain, J.P. (2013). Sociologies de l'alimentation. Les mangeurs et l'espace social alimentaire. Paris: Quadrige.

${ }^{17}$ Eso plantea claramente el problema del abastecimiento en ingredientes culinarios típico de todas las migraciones pero que en Costa de Marfil se ve menos acuciante que en Europa. En España, las tiendas de senegaleses ofrecen productos del país aunque pierden frescura por la distancia, el clima y la conservación.

18 Bouly de LeSDAin, S. (2002). «Alimentación y migración, una definición espacial». En Garabuau-Moussaoui, I., Palomares, E., Desjeux, D., (eds.). Alimentaciones contemporáneas. Paris: 1'Harmattan, pp. 173-189.

${ }^{19}$ CAPONE, S. (2004). «A propos des notions de globalisation et transnationalisation», numéro spécial « Religions transnationales », Civilisations, Bruxelles, vol. LI, no 1-2, pp. 9-22; CAPONE, S. y MARY, A. (2011). « Les translogiques d'une globalisation religieuse à l'envers». En ARGYRIADIS K., Capone S., De la Torre R., Gutierrez C., MARY A. (dir.), Religions transnationales : entre ethnicisation et universalisation, Paris (à paraître). 
compatriotas que no pueden prescindir del attieke $e^{20}$. A mí también me gusta... a pesar de todo, nada puede reemplazar la comida de mi país...es mi origen senegalés que habla aquí...rizas)» (traducido del francés)

Dice el dicho que del gusto y de los colores no se discute por lo que es difícil sacar conclusiones fiables sobre estas afirmaciones de Mbaye. No obstante, a tenor de lo que dice, se infiere que hay evidencias de una existencia del diálogo cultural en el arte culinario. ¿Hasta qué punto? Es difícil de saber ya que la cultura alimenticia de origen permanece, como lo vemos, una expresión de resistencia identitaria. Este intercambio cultural es más bien superficial.

La comida grupal permite fortalecer los lazos de origen. Arjun Appadurai ${ }^{21}$ sostiene, refiriéndose a la India, que la alimentación permite cementar las relaciones entre, por una parte, los individuos y los dioses y, por otra, entre los individuos ellos mismos. Es el caso de los senegaleses en Costa de Marfil. La comida en grupo es un momento de «socialidad» parecido a lo que pudimos también experimentar en España o en Francia. Según apunta Mbaye,

«...una vez a la semana nos encontramos alrededor de un plato de ceb o de mafe. Aquí como en Senegal, nos sentamos en el suelo con el plato en medio. Comemos con las manos o con cucharas...los niños comen aparte, las mujeres también...es el mismo método en mi pueblo de origen...» (traducido del francés)

Para volver a la senda de nuestro argumentación, queremos recordar que para Amy, el restaurante le permitió negociar su entrada en el mercado de trabajo femenino en Costa de Marfil. Desde unos años, otras mujeres que viven en este país, los «peuhl» precedentes de Guinea Conakry u otros países limítrofes se han creado también un tipo de mercado aún más específico: la venta de leche fresca de vaca que proponen a viajeros es estaciones o en mercados informales. Esta práctica fue constatada también por Jacques Barou ${ }^{22}$ en Mumbai, donde los migrantes del

${ }^{20} \mathrm{El}$ attieke es una comida típica de los marfileños y muy apreciado porque es fácil de hacer. Es una especia de Cuscús de mandioca que se come con pescado a la plancha. Se añade cebolla, tomate y pimienta para darle más sabor. Se le suele considerar como una comida económica. No es de extrañar este gusto por lo bueno y barato por parte de los inmigrantes. En Francia pudimos ver también que el Mac Donald se come mucho debido a su bajo precio.

${ }^{21}$ ApPaduraI, A.(2008). «How to make a National cuisine: Cookbooks in Contemporary India». En C. Couniban, P. VAn ESTERIK (eds). Food and culture: A reader: New York: Routledge, 2da Ed.

22 BAROU, J (2010). «L'alimentation, une ressource économique et identitaire pour les immigrés». En Hommes et migrations, 1283.pp. 1-161. 
norte, particularmente los pastores bihari, negocian su entrada en el mercado del empleo vendiendo leche fresca.

La mujer senegalesa cuando no es ama de casa ha encontrado en la restauración el filón perfecto para hacerse un lugar en la sociedad marfileña. Es incluso una fuente de reconocimiento y de identificación, una especie de código genético atribuido a la mujer senegalesa por los marfileños, acostumbrados, desde décadas ya, al famoso ceb bujen senegalés.

En definitiva, el diálogo se manifiesta al nivel social donde los senegaleses verdaderamente no se sienten huérfanos una vez en Costa de Marfil, por el buen trato que aseguran recibir. Esta integración llega a tal punto que, al nivel cultural, sobre todo refiriéndose a la comida, hay intercambios. Todo eso, no significa, como los dijimos ausencia total de problemas. Como en muchas migraciones hay que adaptarse al nuevo entorno y eso pasa por dominar algunas herramientas como el idioma. En este proceso de adaptación intervienen entes sociales étnicos que conglomeran a los senegaleses: se trata de las asociaciones.

\subsection{La asociación para mitigar los problemas preliminares.}

Sobre la cuestión, la larga intervención de Malick, presidente de la asociación de los senegaleses de Treichville, podemos ver el papel que desempeñan las asociaciones de senegaleses en Costa de Marfil:

«Existen muchas asociaciones de senegaleses según la pertenencia étnica, y cada una tiene al menos entre 500 y 900 miembros. Por ejemplo, en la mía somos 842 miembros. Hay algo como 20 asociaciones. En realidad, en cada municipio de Abidjan, hay una gran asociación reconocida por el consulado y a ellas se dirige el consulado cuando quiere dar un mensaje a todos. Por otra parte, existen asociaciones con base religiosa como la Asociación MURIDE que reagrupa, más allá de la pertenencia religiosa a gente que se reconocen en el muridismo. Cada año, ellos organizan al margen de la gran fiesta del muridismo (El Maagal Touba)en Touba, la ciudad del kalifa general del muridismo. Hay otra asociación de aquellos que son de la cofradía TIDIAN que se llama GAMOU. Las asociaciones tienen, todas, un objetivo social. Por ejemplo, las asociaciones dan comida, ropa, dinero y todo tipo de productos de primera necesidad a los recién llegados o a aquellos que pasan necesidades. Ayudamos también a gente que están en la cárcel...algunas se reúnen el domingo, y hacen cotizaciones semanales, otras se reúnen cada mes con cotizaciones mensuales. Cuando hay acontecimientos (fiestas, funerales, bautismos, bodas, etc.) hay cotizaciones excepcionales... El monto difiere según la asociación. Algunas se elevan a 2000 francos. Existen también asociaciones de gente que viven en 
el mismo barrio y que cuenta con 20 o 50 personas. Y cada ciudad en Costa de Marfil tiene su asociación. Hay algunas asociaciones como la nuestra que tiene un despacho en el que alguien se ocupa de la permanencia. Los miembros, fuera de los días de reuniones, vienen a presentar sus preocupaciones...» (traducido del francés)

Las limitaciones y los problemas que encuentran les senegaleses, recién llegados o no, se solucionan fundamentalmente a través del apoyo mutuo de la red migrante. En efecto, todas las asociaciones senegalesas han creado un sistema de alojamiento y de ayuda, algo común a todos los senegaleses en otras partes del mundo. Le diutigui, según Malick, término que se atribuye a alguien que aloja a un viajero, desde siglos sigue en pie. A eso se añade las tradicionales formas de solidaridad africana que, en los casos de los senegaleses en inmigración adopta el carácter de Ley. Entre los Wolof, los Halpular, la solidaridad fraterna adopta el nombre de (fedde). Esta fraternidad puede ser consanguínea pero también tiene que ver con la clase de edad, según Malick:

«Para nosotros, la gente de la clase generacional son incluso más que hermanos de sangre. Los hermanos de la clase de edad nunca te dejan caer cualquier que sea el problema...Entonces, cualquier que sea el lugar donde se encuentren si llegas a ellos, te reciben y se ocupan de ti...» (traducido del francés)

En la comunidad, la ayuda no se limita a la acogida, al sustento sino también a la consecución de un trabajo o en la realización de una actividad comercial o también de un aprendizaje. En inmigración, eso es visible pero no es motivo para creer que en Senegal, la gente vive a costa de los demás. Salvo, en situación de emigración hacia la capital, o los centros urbanos como Touba, Diourbel y demás, la gente dispone de su habitación o de su casa. Esta forma de solidaridad es pura coyuntura e incluso tiende a desaparecer según Tidjan:

«...yo no tuve la misma suerte que los demás. Tuve que alquilar una habitación en Adjamé con amigos. Yo vine en tiempos difíciles y la asociación no tenía un funcionamiento normal. Cada uno pensaba a su propia suerte...también es verdad que tampoco buscaba mucha compañia...porque yo prefiero estar con los murides...» (traducido del francés)

Eso se sostiene. En efecto, la pertenencia a una cofradía significa mucho en la estrategia de inmigración. Los lazos religiosos son igual de fuertes o más que los lazos familiares o de clase de edad. Y el hecho de no pertenecer a la misma cofradía puede significar mucho a la hora de encontrar un alojamiento.

Dado, el empeño en el ahorro, el ocio, la diversión, la participación social de los 
inmigrantes senegaleses, pasa, en muchos casos, por su relación con la colonia de origen que reside cerca, según Malick. Organizan visitas a las diferentes casas de los senegaleses y se celebran fiestas religiosas significativas para la comunidad. francés)

«...nuestra diversión es visitarnos los unos a los otros...» (traducido del

Incluso en estas circunstancias, uno se puede acoger a la asociación. Étnica o religiosa. El dinamismo de estas asociaciones, como nos lo significó Malick, se ha vista mermado a causa de las cotizaciones que no se pagan. Eso dificulta la acogida de los nuevos.

«...Antes, incluso teníamos casa de acogida de unas habitaciones. En caso de problema incluso los particulares podían acoger a los nuevos en nombre de la asociación. Ahora, la crisis hace que la gente no puede seguir haciendo eso...» (traducido del francés)

Es difícil hablar de regularidad en el pago de las cotizaciones debido a la inestabilidad profesional de los migrantes senegaleses. Muy a menudo, buscan primero una estabilidad financiera aunque deban primero apoyarse en la asociación y recurrir a ella en caso de problemas como en el caso de Mouss:

«...antes no veía la importancia de la asociación. Huía incluso de ellas porque no tenía suficiente dinero para pagar siempre lo que se pedía. Un día tuve un problema con un joven marfileño de mi barrio a causa de una chica que venía a visitarme en mi lugar de venta. No sabía que era su mujer ...vino a amenazarme de muerte...iba en serio porque nos buscaban a nosotros los extranjeros. Tuve que esconderme durante cierto tiempo...me fui a ver Malick presidente de la asociación de los senegaleses de Treichville. Como es muy conocido, se fue a ver al jefe de los ébriés, para pedir perdón a este joven ...» (traducido del francés)

Para Sylvie Bredeloup ${ }^{23}$ (1995) esta desafección se explica por el hecho de que, en realidad, muchos migrantes no comparten la misma visión de desarrollo. Por eso, no están dispuestos a financiar la supervivencia de la asociación.

Los lazos étnicos, religiosos son los principales motores de la solidaridad y en ello, la dahira mouride juega un papel decisivo. Las estructuras comunitarias constituyen, es verdad, un cuadro virtual de solidaridad pero son insuficientes para asegurar la inserción de los nuevos. Resulta, no obstante, que el sistema de

${ }^{23}$ Bredeloup, S. (1995). «Sénégalais en Côte-d'Ivoire, Sénégalais de Côte-d'Ivoire». En Mondes en Développement : Dynamiques migratoires et recompositions sociales en Afrique de l'Ouest, vol. 23, 91, 1995, p. 13-29. 
relaciones interindividuales tiene a tomar el paso sobre las estrategias de grupo principalmente entre los neo-migrantes con la adhesión à uno o dos redes extra étnicos de sociabilidad. Estos lugares constituyen tantos lugares de recomposición identitarios que dan a los espacios migratorios un carácter transnacional

La apuesta de vivir lejos de su país, preservando una estrecha proximidad con el territorio de origen hace que los inmigrantes senegaleses se impliquen más bien muy poco en las dinámicas sociales de nuestro país. Esta elección le obliga a contar con la capacidad de su red a superar los problemas a los cuales se enfrenta como encontrar trabajo para poder mandar dinero a sus familiares en el país de origen.

\subsection{Crisis y rotura del diálogo}

Una estancia prolongada en un país no siempre es sinónimo de instalación definitiva y los senegaleses en Costa de Marfil siguen la misma pauta. En periodos de crisis el proyecto migratorio puede acortarse. En Costa de Marfil, la crisis que se vivió hizo que el país, fuera visto más en tanto que trampolín para emigrar hacia países como Gabón o Francia, o en caso de fracaso del proyecto migratorio, una zona de repliegue.

Es verdad, la crisis ha afectado tanto a los senegaleses como a los propios marfileños, incluso en la distancia. Esta situación obligó a muchos a volver a Senegal a causa de la inseguridad que reinaba. Muchos senegaleses de Treichville han visto como saqueaban sus tiendas de ropas y demás aparatos electrónicos.

Resituemos esta crisis. El 19 de septiembre de 2002, Costa de Marfil sufre un golpe estado que no llegó a concretarse. Los asaltantes prepararon el golpe desde los países vecinos como Burkina Faso y Mali. La partición del país en dos acabó de consagrar una cierta repulsión hacia todas las personas que vienen de Burkina Faso $\mathrm{y}$, a la larga, hacia todos los extranjeros. No obstante, los senegaleses tenían buen trato. Un trato que empezó a cambiar.

En efecto, la familiaridad y la fraternidad que existía han ido transformándose por el discurso xenófobo que empezó a imperar en Costa de Marfil. Antes el senegalés era considera como un inmigrante muy amable y no conflictual. Era valorado más aún que un libanés. El gorgi como se les suele llamar ha ido perdiendo, igual que todos los extranjeros en Costa de Marfil, el estatus privilegiado de que gozaba. Este estatus privilegiado venía de lejos. En efecto, como decíamos en las primeras páginas, los primeros senegaleses se instalaron décadas antes de la independencia del país. Se opusieron de manera pasiva al poder colonial mostrando así su simpatía con el país. Perdieron su peso económico a causa de esta actitud cuando, en represalias, los colonos prefirieron trabajar con 
agentes sirios-libaneses en vez de con ellos. Además, la buena relación que entretenía el presidente Felix Houphouët Boigny, primer presidente del país, con el expresidente senegalés Leopold Sedar Senghor y más aun con Abdou Diouf, su sucesor ha hecho que el senegalés sea considerado como el amigo, el hermano. Esta situación ha cambiado radicalmente cuando el presidente Abdoulaye Wade, en Dakar, durante una conferencia internacional sobre el racismo y la discriminación, el 22 de enero de 2001 tomó a Costa de Marfil para ilustrar su argumentación diciendo: «en este momento en el que os hablo, un burkinés vive lo que ningún negro vive en Europa».

Lo que sólo tenía que ser un intento de aumentar su capital estima entre los occidentales tuvo una repercusión terrible. Esta frase empezó a circular en los puntos de propaganda del presidente Laurent Gbagbo ${ }^{24}$ tales como los «agoras» y le valió a la comunidad senegalesa una ola de críticas sólo por lo que dijo su presidente. Los senegaleses llegaron incluso a manifestar públicamente su reprobación a las palabras de su presidente. Su actitud tuvo incluso una repercusión en Senegal donde se acusaba al presidente de poner en peligro la vida de sus ciudadanos en un país donde la comunidad senegalesa era respetada, y sobre todo en una situación tan sensible como la que conocía Costa de Marfil en aquel entonces. Bamba, un estudiante senegalés que vivía en León, reaccionaba así a esta desafortunada salida de su Presidente:

"Creo que no tenemos a un presidente temerario sino a un Presidente idiota que no sabe cuidar de las relaciones. Es verdad que todos sabemos lo que el extranjero vive en Costa de Marfil pero no era necesario que se pronunciara de esta manera cuando sabemos el peso de la comunidad senegalesa en este país. Ahora cuando vuelvan, buscará cómo ayudarles. Eso le pasa por bocazas» (traducido del francés)

La crisis ha modificado la calidad de las relaciones de los marfileños con senegaleses pero también ha modificado sus costumbres migratorias. Los comportamientos tradicionales de los migrantes empezaron a cambiar y a cambiar para siempre. Ahora, los hermanos no son bienvenidos por temerarios a pesar de sus advertencias. Se anima, desde el país de origen, a los jóvenes a cambiar el sino de su proyecto migratorio. Con la crisis, el país ya no era rentable, además con el ambiente xenófobo existente, lo mejor era buscar otro destino. Muchos renunciaron

${ }^{24}$ El presidente marfileño se agarraba al nacionalismo para conservar el poder. Los jóvenes llamados «jeunes patriotes» se reunían en estos foros para disecar la situación del país. Allí se identificaban según criterios propios, quienes están en contra del país o no. De allí se dictaminaban las sentencias, se incriminaba, se decidía quién había que tachar de enemigo. El senegalés, antes el hermano, se había convertido desde entonces en enemigo. 
por lo tanto a la reagrupación comunitaria para pensar en una nueva estrategia migratoria destinada a acercarse más a los autóctonos. Algo que en su tiempo era más bastante raro teniendo en cuando los lazos de solidaridad que evocamos. Es un comportamiento que se asemeja a los que hemos observado en países como España o Francia. En estos países, si la «territorialización» es algo común para los nuevos inmigrantes, a medida que se van haciéndose con la cultura local, hay una tendencia a cambiar de residencia, a alejarse, incluso en la forma de vivir su cultura de origen.

\section{CONCLUSIÓN.}

La migración senegalesa en Costa de Marfil adopta una estrategia colectiva orientada hacia las grandes ciudades donde las posibilidades económicas son grandes para sus negocios. Abidjan es la ciudad donde vienen a empezar un sueño o a realizarlo, conservando escrupulosamente su modo de vida, sus costumbres alimenticias, sus prácticas religiosas y asociativas. Tanto por razones familiares como profesionales, los hombres vuelven a su país, considerando Costa de Marfil como un punto en su espacio de vida. Entre las comunidades extranjeras en el país, la senegalesa siempre ha sido la más cercana en la estima de los marfileños. La crisis, que conoció el país, echó abajo esta fraternidad exacerbado por el brote de un nacionalismo violento orquestado por los políticos durante el conflicto. La predisposición de los senegaleses a volver para contribuir al bienestar de los suyos en origen se vio reforzada cuando muchos tuvieron que volver a la fuerza. La crisis siempre es un factor que milita en contra de los inmigrantes ya que se les suele achacar la falta de empleos, de recursos económicos. Es una situación que también se ha observado en España y en otros países europeos, como Francia. La crisis, como se ha mostrado en nuestras investigaciones, ha modificado las relaciones entre comunidades marfileñas y senegalesas. Hace falta «reanudar el diálogo» Si el continente africano quiere desarrollarse, hay que facilitar tanto la convivencia económica, cultural como social entre los africanos cualquier que sea el país africano donde residen y viven. Serge Latouche ${ }^{25}$, al respecto, cita a Pablo VI que, en su Encíclica Populorum progressio, afirmaba: «para ser auténtico, debe (desarrollo) ser integral...» Las organizaciones tales como la CEDEAO (Comunidad de les Estados del África del Oeste) de la que forman parte Costa de Marfil y Senegal así como otros países de la región oeste africana debe dar un paso más adelante. En Costa de Marfil, el diálogo intercomunitario debe extenderse no solo a los senegaleses sino también a los demás países de la región y a todo aquel que vive en el país. El ostracismo no es beneficioso para ningún país y, tanto en

${ }^{25}$ Latouche, S. (2004).Survivre au développement. Clamecy: Mille et une nuits, p. 26. 
África como en Europa, las organizaciones deben servir para fraternizar y no solo para las necesidades económicas. Esta situación tiene un parecido con lo que ocurre en Francia aunque a un grado menor ya que este país no conoce la guerra pero si la crisis. En este país, la cuestión de los Roms (los rumanos) nos da una idea de «los cortafuegos» que ponen los países a la hora de proteger sus economías particulares. Interesa tener un mercado amplio para vender y no otra cosa. ¿Cabe preguntarse de qué sirven las organizaciones como la UE o la CEDEAO que nacieron para acabar con las fronteras si en tiempo de crisis se mira a los particularismos en vez de ayudarse de forma solidaria? De momento, Costa de Marfil no lo ha sabido hacer con los senegaleses, los malíes o los burkineses que vinieron a hacerla próspera en tiempos ya remotos. En 1958, Felix Houphouet Boigny que inicialmente se opuso al proyecto de conjuntos federales para las colonias diciendo que Costa de Marfil no puede ser la vaca lechera del África occidental francófono (AOF), tuvo que recapacitar porque entendió que sin los demás, el país no podía enfocar su desarrollo hasta alcanzar el famoso «milagro marfileño». Si los africanos no podemos ayudarnos, ¿cómo se puede esperar una ayuda desinteresada por parte del resto del mundo? Es tiempo de pensar en ello ahora, y el estudio antropológico de la comunidad senegalesa en Costa de Marfil es un pretexto para abrir el debate, un debate en el que esperamos contribuciones, no solo de los africanos sino también de los europeos, en una lógica de apertura de fronteras y de diálogo franco y constructivo. 